\title{
"DOMINANDO" OS BÁRBAROS: \\ Barbados, ativismo abolicionista e classificação da pena de morte
}

\section{Brackette F. Williams}

\section{Introdução}

Estamos imersos em classificações. Como sugerem Bowker e Star (1999, p. 26), cada vez mais habitamos, e aprendemos a pensar, as categorias produzidas pelos esquemas classificatórios. Numa "sociedade classificatória", tais esquemas formais e informais fornecem as grades que nos formam, ao mesmo tempo em que nós os formamos. Eles fazem dos "seres humanos" uma gama de "nós" e "eles". Usamo-los para juntar, dividir e juntar novamente as pessoas, para criar segmentações úteis entre grupos. Não há nada mais humano do que classificar, e nada potencialmente mais destruidor do ser humano. Ao cumprirmos as tarefas que tornam possível a vida, produzimos centenas de esquemas classificatórios. Tentamos solidificar

Tradução de Paul Freston os aspectos úteis desses esquemas, e elaboramos práticas para administrá-los como parte da definição e da resolução de problemas. Nas tarefas diárias, a forma como classificamos - o número de modos de classificação que estabelecemos e a tolerância diferenciada com que os tratamos - produz conseqüências positivas e negativas para a maneira como seres humanos dentro e entre populações navegam as percepções alheias sobre o "real", o "bem" e o "mal".

Esquemas classificatórios locais, usando modos alternativos de classificação, cedem o passo à infra-estrutura cada vez mais complexa e intricada de um sistema classificatório internacional. O modo singular de classificação desses esquemas diminui a margem para o pensamento criativo das populações. Os povos, como cidadãos das unidades governamentais menos poderosas em termos econômicos e políticos, têm menos oportunidade para participar no estabelecimento dos esquemas 
formais de classificação internacional. Ao estabelecerem esquemas locais de classificação para definição e resolução de problemas, eles têm cada vez menos espaço do que os seus semelhantes em Estados mais poderosos. Os ativistas das reformas sociais, no afã de eliminar vestígios de "barbárie", adotam um modo de classificação sobre o qual as unidades governamentais mais poderosas têm mais controle; assim, suas atividades bem-intencionadas podem colaborar para a subordinação dos Estados menos poderosos aos mais poderosos. Quando, na prática, os ativistas aceitam pressuposições que reivindicam um esquema de classificação formal, e o modo de classificação deste oferece a melhor base para assegurar decisões objetivas e racionais, a maneira em que promovem tal modo facilmente reintroduz soluções universais e práticas imperialistas. Para problemas morais complexos, as unidades governamentais menos poderosas se encontram numa terra-de-ninguém moral quando tentam usar modos alternativos de classificação. As mais afastadas (outliers), que não se encaixam nos requisitos de uma estrutura taxonômica e de um processo, são facilmente acusadas de bárbaras, por resistir à eliminação da barbárie da ordem social moderna ou pósmoderna.

O presente artigo investiga o papel da classificação nas estratégias abolicionistas para a pena de morte. Referimo-nos ao modo favorecido como o modo dominante de classificação, sugerindo que o bem-intencionado ativista social internacional, ao aceitar esse regime classificatório na prática, acaba tornando-se cúmplice na promoção de práticas imperialistas. Analisamos, em primeiro lugar, a classificação abolicionista das unidades governamentais na constituição do universo no qual medem o progresso em direção à abolição mundial. Em segundo lugar, examinamos como os abolicionistas, aliados às cortes internacionais incumbidas de aplicar as convenções de direitos humanos, elaboram estratégias que dependem de contestar a estrutura e o processo taxonômicos que resultam do modo dominante de classificação. Elaborando estratégias, eles respondem ao modo dominante de classificação - minando os conceitos adversos e expandindo os conceitos moralmente úteis. Esquemas e processos classificatórios de pena de morte que oferecem pouco do material conceitual do qual suas estratégias dependem criam dificuldades estratégicas para os ativistas. Buscando formas de contestar tais esquemas, ativistas promovem o pressuposto de objetividade e racionalidade para o modo de classificação. Embora críticos desses esquemas e processos, que consideram desumanos e desvalorizadores da vida (de transgressores e transgredidos), eles acabam promovendo a submissão ao modo de classificação como forma de controlar os outliers, os bárbaros da fronteira, que precisam ser domesticados pela maneira em que o modo opera a objetividade e a racionalidade.

Os Estados política e economicamente fracos, que por muitas razões que não o consenso moral ratificaram as convenções de direitos humanos mas não as incorporaram no seu direito interno, confrontam-se com uma aliança de abolicionistas e cortes internacionais que minam seus poderes constitucionais ao colocarem-nos em oposição aos pressupostos de objetividade e racionalidade do modo dominante. Para ilustrar a dinâmica decorrente, falaremos de Barbados como uma unidade governamental pequena e política e economicamente fraca, que tenta usar um esquema e processo classificatórios de pena de morte incompatível com elementos essenciais do modo dominante de estrutura e processo. Embora insistindo na primazia de suas determinações constitucionais para a pena de morte e a superioridade moral e prática de sua "abordagem integrada à misericórdia", analisaremos como Barbados falha, mesmo ao recorrer à Corte de Justiça Caribenha como corte de última instância, na tentativa de agir de acordo com suas determinações constitucionais.

Embora a tarefa de acabar com a pena de morte seja louvável, e até essencial, este artigo questiona se os ativistas, ao insistirem na submissão ao modo dominante de classificação, não se tornam cúmplices na expansão de práticas imperialistas visando a reanimar (ou continuar) um legado colonial de dependência cognitiva.

\section{Classificando os classificadores}

Para medir o progresso em abolir a pena de morte, os abolicionistas dividem o mundo em duas categorias primárias - abolicionista e retencionista. Países abolicionistas aboliram a penalidade para todos os crimes ou apenas a retiveram para crimes extraordinários. Os países retencionistas, que preservam a penalidade na lei, são recategorizados pelos 
primeiros como países abolicionistas por política ou prática. Unidades retencionistas abolicionistas são aquelas que exprimem uma política, escrita ou nãoescrita, contra a imposição da lei. Outros, embora não afirmem essa intenção, são abolicionistas se eles não emitem sentenças ou não aplicam a penalidade há certo número variável de anos. Com essas classificações, abolicionistas produzem o que Kronenfeld (1996) chama de estrutura mágica septagonal, que é uma unidade nuclear para construir estruturas taxonômicas. A razão de classificarem desta forma revela o motivo para a sua classificação - apresentar a visão mais positiva possível de uma tendência à abolição mundial. Expandir o número de países abolicionistas, por meio de critérios que permitem reclassificar unidades inicialmente retencionistas, permite-lhes listar 120 países abolicionistas - mais de metade das 227 unidades governamentais do mundo. Conseguem este quadro positivo convertendo homogeneidades heterogêneas (conjuntos de igualdades variadas) com uma oposição inicial (retenção e abolição), num número maior de heterogeneidades homogêneas utilizáveis (usando aspectos limitados de variação para constituir igualdades aceitáveis). Estas últimas, então, tornam-se disponíveis para juntar novamente em novas e maiores homogeneidades heterogêneas aceitáveis.

Apesar do quadro róseo de progresso que essa conversão apresenta, oito das dez unidades governamentais mais populosas do mundo estão entre as 76 soberanias retencionistas "plenas". Na categoria abolicionista expandida, 84 são dependências coloniais. Estas, como Porto Rico, que tem uma provisão constitucional proscrevendo a pena de morte, são subordinadas a unidades governamentais soberanas e as provisões constitucionais destas. As unidades soberanas independentes que são "retencionistas-plenas" expõem à pena de morte mais que 4 bilhões da população mundial de mais de 6 bilhões (The World Fact Book, site www.cia.gov/cia/publications/fact book/geos/ja.html, julho de 2005). Quatro unidades soberanas retencionistas-plenas (Estados Unidos, Indonésia, Paquistão e Bangladesh) juntas governam 50 milhões a menos que a Índia, que é a segunda mais populosa unidade retencionista.

Confrontada com a capacidade de Estados poderosos de resistirem à intervenção classificatória internacional, os abolicionistas desenvolvem uma “estratégia de desgaste lenta”. Procuram conceitos, como elementos de estrutura e processo classificatórios operando nesses Estados, para atingir conceitos vulneráveis. Quais conceitos são vulneráveis depende, em parte, das mudanças na estrutura e no processo classificatórios da pena de morte, na medida em que o público responde a esses conceitos. A resposta pública pode ter uma influência direta, mas geralmente a mudança conceitual advém indiretamente das definições e práticas que empregaram o mesmo conceito como parte de vários esquemas de classificação. Por exemplo, o interesse público crescente pelo bem-estar infantil, e esquemas de classificação estabelecidos para oferecer proteção legal à criança em geral, à criança em risco ou à criança abusada, providenciaram munição para estratégias contra a pena de morte que atacaram o "menor" como conceito vulnerável em esquemas de pena de morte. As conseqüências de mudanças classificatórias adentram as infraestruturas da classificação legal internacional, pois algumas leis domésticas servem como precedentes e jurisprudência, influenciando decisões nas cortes internacionais. De modo inverso, a subseqüente mudança no direito internacional pode influenciar as decisões no direito doméstico para produzir uma tendência modernizante no direito de forma geral, mas as unidades soberanas mais poderosas são mais capazes de resistir aos esforços de compatibilizar suas provisões constitucionais para a pena de morte com as consequências de tais mudanças, as quais influenciam os esquemas internacionais de classificação. As unidades governamentais menos poderosas, mesmo aquelas que são soberanias independentes, têm menos poder para lidar com a pena de morte como questão de direitos humanos de acordo com as suas provisões constitucionais.

Conseqüentemente, as soberanias independentes politicamente fracas que mantêm a pena de morte enfrentam desafios às suas provisões constitucionais dos ativistas de direitos humanos que promovem, como um modo dominante de classificação, esquemas e processos de classificações sobre os quais as soberanias mais poderosas têm maior controle. Embora as provisões constitucionais pareçam oferecer, às unidades governamentais soberanas, controle sobre a visão moral para administrar a pena de morte, esta aparência é ilusória para as unidades mais fracas, pois os precedentes legais transcendem as jurisdições nacionais, mesmo quando o direito interno dos Estados fracos chega 
a incorporar as provisões dos tratados de direitos humanos que eles assinam. As cortes internacionais, encarregadas de obrigar a adesão, também são favoráveis à abolição da pena de morte.

A investigação das respostas abolicionistas e das cortes internacionais à classificação da pena de morte em Barbados, um Estado soberano, revela como seus adversários promovem o modo de classificação dominante. Eles apontam conjunções que julgam dever existir entre provisões constitucionais e convenções de direitos humanos. A classificação nacional deve ceder à perspectiva do modo dominante sobre como aplicar as convenções internacionais de direitos humanos, as quais se emaranham numa infra-estrutura internacional de sistemas classificatórios (Bowker e Star, 1999).

\section{Constituição, ativistas, cortes e disciplina classificatória}

Pela constituição, Barbados mantém a pena de morte. O Estado seleciona o ato que qualifica para a morte a pessoa transgressora. $\mathrm{O}$ seu esquema de pena de morte não é único, mas raro, pois há apenas um ato - o homicídio - para qualificar tanto a transgressão como o transgressor. Até o presente momento (2007), o país não executa ninguém desde 1984. É signatário da Convenção Internacional sobre os Direitos Civis e Políticos (ICCPR) e da Convenção Americana sobre Direitos Humanos (ACHR) de 1978. Como membro da Organização dos Estados Americanos, Barbados aceita a sua Carta de Direitos Humanos, modelada na Declaração Americana dos Direitos e Deveres do Homem (ADRDM) de 1948. Antes da ocorrência do caso que analisaremos, o país havia aceitado a jurisdição compulsória da Corte Interamericana de Direitos Humanos (IACHR), que julga a conformidade com o ACHR. Os problemas enfrentados por ter um regime de monarquia constitucional permitem-nos entender que o conceito de soberania, como glosa de poderes constitucionais, denota homogeneidades heterogêneas para unidades governamentais e, com isso, o seu potencial de responder às inconsistências entre como eles administram as provisões constitucionais que conflitam com o modo dominante de classificação.

Até a sua independência em 30 de novembro de 1966, Barbados, como colônia britânica, repro- duziu revisões do direito inglês no que concerne crimes contra a pessoa. Após a independência, as mudanças foram consistentes com o espírito do esquema classificatório herdado. Já em 1957, com a aprovação da Parte II da Lei de Homicídio (Homicide Act), a Inglaterra fazia distinção entre o homicídio capital e não-capital, atenuando a penalidade a ser aplicada a este último. Em 1965, a Inglaterra aboliu a pena de morte com a aprovação da Lei do Homicídio doloso (Murder Act) e a comutação da Seção 1 da Lei sobre Transgressões contra a Pessoa, de 1861, que havia estipulado: "Quem for condenado por homicídio doloso deve sofrer morte como criminoso". Como monarquia constitucional, até 1994, Barbados manteve a Lei sobre Transgressões contra a Pessoa, de 1868, cuja Seção 2 se pautava na Seção 1 da lei inglesa de 1861. Na Lei de 1994, a Seção 2 afirma: "Qualquer pessoa condenada por homicídio doloso será sentenciada, e sofrerá, morte".

A Seção 1 da constituição, ao afirmar que "Se qualquer lei for incompatível com esta Constituição, prevalecerá a última, e a lei será nula na medida de sua incompatibilidade", tornou a constituição a lei da nação. A Seção 26 imuniza as leis pré-constitucionais de incompatibilidades, afirmando que uma lei "não será considerada incompatível com, ou em contravenção de, qualquer provisão das Seções 12 a 23 ".

O Capítulo II protege "os Direitos e Liberdades Fundamentais do Indivíduo", com a Seção 15(1) assegurando que "ninguém estará sujeito a uma punição degradante ou desumana".

Essas provisões são agora o primeiro recurso para os que contestam a constitucionalidade da pena de morte em Barbados. Sua forma de soberania lhe subordina ao Conselho Privado (BCP), a mais alta corte recursal, enquanto as convenções e os tratados de direitos humanos que o país aceitou entre 1976 e 1982 tornam possível o recurso dos seus cidadões às cortes internacionais que exigem a conformidade. Opositores da pena de morte e advogados de defesa argumentam contra a Seção 26 da constituição, que dá imunidade para leis existentes antes da independência. Para eles, não deveria imunizar as leis contra a Seção 15 (1). Em vez disso, eles a interpretam no sentido de exigir a compatibilidade entre o direito interno e os tratados internacionais de direitos humanos dos quais Barbados é signatário. Houve, em 2002, um cruzamento 
entre estascontestações e outras que emanam dos precedentes legais internacionais sobre sentenças obrigatórias.

O Recurso n. 99 do Conselho Privado, de 7 de julho de 2002, no caso de dois homens condenados por assassinar um homem, sugere que a constitucionalidade é apenas a aparência exterior de um esforço do modo dominante de classificação por tratar o país como um outlier em termos de suas práticas. Esse recurso seguiu duas decisões da Corte Interamericana sobre pena de morte, uma em 2001 e a outra em junho de 2002. Na primeira, a decisão confirmou a sentença dada pela Corte de Apelação do Leste Caribenho (ECCA) contra a sentença de morte obrigatória e, na segunda, ela ordenou Trinidad e Tobago a atualizar o seu esquema de pena de morte, de 1925, a revisar a sua sentença de morte obrigatória e a elevar as condições de suas prisões aos níveis internacionais. ${ }^{1}$

Lord Hoffmann, pronunciando a decisão majoritária no Recurso n. 99, resumiu a história do envolvimento barbadiano com tratados de direitos humanos, notando que a jurisdição compulsória da Corte Interamericana foi quase aceita, embora não incorporada, quando Barbados enforcou três pessoas condenadas à morte em 1984. Para o recurso de 2002, a decisão majoritária apontou que, entre 1967 e 2000, as convenções de direitos humanos detalharam cada vez mais os direitos fundamentais, "a obrigação [do Estado] de evitar puniçãos degradantes e humilhantes, e o seu dever de promover a vida, liberdade e segurança da pessoa"; mesmo assim, estas convenções não chegaram a proscrever a pena de morte. Dos anos de 1990 em diante, a Comissão Interamericana, a Corte Interamericana e o Comitê de Direitos Humanos das Nações Unidas deram pareceres contestando a sentença de morte obrigatória por ser arbitrária e desumana. A corte achou-a incompatível com a ADRDM, a ACHR e a ICCRP. Para os abolicionistas, essa contestação abriu alternativas para o que os ativistas geralmente chamam de "estratégia do desgaste lento" - mudanças incrementais visando à abolição na prática, em direção à abolicão legal.

A atenção da corte e dos abolicionistas ao conceito obrigatório do esquema revela a maneira pela qual se opõem unidades governantes outliers, como Barbados, às exigências de compatibilidade com o modo dominante de classificação. Ao in- cluir sentenças obrigatórias, para esquemas classificatórios que não têm agravantes, os promotores da estratégia do desgaste lento têm apenas um conceito para empregar na codificação da ordem moral. Uma contestação aos esquemas e às práticas classificatórios, conceito por conceito, admite a reconfiguração do conceito de humanidade, de forma a remover o conceito, e a sua estrutura e prática associadas, para criar uma objetividade e racionalidade que liguem adequadamente os bons costumes e a moralidade. A obrigatoriedade já era um conceito vulnerável e "ruim", resultado de casos de pena de morte ouvidos na Suprema Corte Americana em 1976 e 1977, que vinculavam a obrigatoriedade à barbárie, mas apenas para a classificação da pena de morte. A obrigatoriedade tornou-se um conceito "bode expiatório", sacrificada para produzir material apropriado de meios classificatórios no sentido de incentivar a compaixão sob a Oitava Emenda, Seção 1983 da Constituição dos Estados Unidos (Woodson v. North Carolina 1976, 428 US 280, e Roberts v. Louisiana [1977, 431 US 633]).

Entre 1999 e 2002, considerando as posições da Suprema Corte dos Estados Unidos, a Corte Interamericana invetsigou a sentença de morte obrigatória nas Bahamas, em Barbados, Belize e Trinidad e Tobago. Embora a posição majoritária tenha notado que estas unidades governamentais já administravam esquemas de pena de morte quando se tornaram signatários de convenções de direitos humanos, estes não proporcionaram mais nenhuma ofensiva, pois lhes faltava a estrutura agravanteatenuante que os esquemas do modo dominante proporcionam às ofensivas contra conceitos múltiplos. No antigo regime classificatório, estados que se tornaram outliers haviam limitado a penalidade aos homicídios dolosos, mas sem distinguir os homicídios dolosos capitais para restringir o seu uso. A maioria das unidades governamentais usava a categoria de transgressão única e o esquema de sentença única. Isso significava que os promotores do modo dominante só podiam atacar a fusão discricão-arbitrariedade. A posição majoritária, ao identificar a fonte da mudança na atitude social, também indiretamente identificou essa questão subjacente. Concluiu, portanto, que: "A objeção à penalidade de morte obrigatória é que os atos que se encaixam na definição de homicídio doloso (sobretudo quando estendido à regra homicídio doloso/crime) variam muito em termos da repreensibilidade moral" 
(Lord Hoffmann, Posição Majoritária, Recurso no Conselho Privado, n. 99 de 2002, p. 7).

A posição majoritária contra-argumenta que Barbados reconhece a variação dos homicídios dolosos, o que tem implicações morais para a repreensibilidade, e considera que seus procedimentos respondem adequadamente a esses problemas. Com isso, a posição majoritária afirma que "O governo sempre aceitou que a execução de todos os condenados por homicídio doloso seria inaceitavelmente severo e indiscriminado - de fato, cruel e desumano". A resposta revela sua falha, ou recusa, de entender a supostamente maior objetividade do processo de classificação bifurcante que requer categorias preestabelecidas. Ao contrário, enxergando este processo como contrário a resultados justos, a posição majoritária permanece comprometida com uma alternativa integrada. Ela reivindica que essa alternativa, como uma união integral de processo e prática, proporciona mais justiça para transgressores e mais segurança para a comunidade transgredida. Portanto, o suposto maior valor da primeira distinção-chave - judicial e executiva -, na qual o modo dominante se apóia, não melhora a justiça na opinião da posição majoritária.

Portanto, a posição majoritária sustenta: "o governo argumenta que as provisões para a aplicação da pena de morte devem ser consideradas como um todo, e que isso inclui o poder do Governador-Geral". Para a posição majoritária, o processo é humanitário porque o Governador-Geral, “aconselhado pelo Conselho Privado de Barbados, revoga a sentença de morte em qualquer caso que ele considerar apropriado fazê-lo". Em resumo, tal posição é favorável a uma unidade integral ("justiça" como um todo homogeneizado) que não estende própria e formalmente a estrutura de seu esquema classificatório. Sua estrutura e processo de classificação obscurecem distinções que deveriam tornar claras. Ela não tem duas ramificações nas quais colocar pedidos ad misericordiam, sem as quais a estrutura permanece vulnerável a acusações de "homicídio arbitrário" por "discrição" imprópria, mas, mais importante, aplica discrição a pessoas que a classificação ainda não formou adequadamente.

Por séculos, filósofos e eruditos legais argumentaram que considerar tais pedidos antes da declaração de culpa e da sentença judicial produz resultados injustos e irracionais (já que tomadas com emocionalismo) (Walton, 1997). As exigências do modo dominante de classificação para um esquema adequado e formal de pena de morte não aceita esse ponto de vista. Em vez disso, reivindica meios de colocar material do pedido em toda parte da estrutura e do processo. Já que a estrutura é feita por uma gama contínua de nivelamento e ramificação simultâneos, inserir este material proporciona o necessário para transformar heterogeneidades homogêneas em homogeneidades heterogêneas categóricas, usuais mas nunca estáveis.

A posição majoritária continua o seu argumento para um todo integral, insistindo: "A Constituição codifica e institucionaliza o exercício da prerrogativa real da misericórdia que era exercida sob orientação do Ministro do Interior quando a pena de morte existia na Inglaterra" (Recurso Hoffman, n. 99 de 2002, p. 7). A posição majoritária obstinadamente, digamos, "compreende mal" que essas funções são agora parte de um encaixe pela distinção-chave "processo-em-estrutura". O modo dominante de classificação exige primeiro ad misericordiam como simplificação categórica preestabelecida pelas instâncias judiciais. A clemência avaliaria formas pré-digeridas de personalidade como se fossem de fato "indivíduos" buscando a misericórdia. O modo dominante de classificação faz, portanto, um todo ao inserir, na estrutura e em todo o processo, as bases para a objetividade.

Apoiando-se em seu processo integrado único, a posição majoritária argumenta que as autoridades se engajam no todo porque isso é necessário para o princípio da dissuasão, promovendo a segurança do cidadão. $\mathrm{O}$ todo que inclui a clemência como passo final é também a medida da justiça ministrada humanitariamente para pessoas condenadas, mas não uma forma preestabelecida de personalidade. Assim, tal posição conclui:

O governo diz que quando se leva em conta e examina a operação da pena de morte na prática, ela não é rígida ou arbitrariamente aplicada. Argumenta ainda que a sentença obrigatória permite à lei conseguir máxima dissuasão, enquanto o poder de comutação proporciona a flexibilidade e o humanitarismo necessários em sua aplicação prática (Hoffmann, Recurso n. 99 de 2002, p. 7).

Apesar do ato qualificatório e da sentença únicos, o parecer categórico está sempre presente no esquema de Barbados, pois algum tipo de clas- 
sificação é sempre parte da tomada de decisões. Porém, por causa da sua "informalidade", como teste da equidade processual ele permanece sujeito à fusão "discrição-como-arbitrariedade". Os critérios resultantes para a escolha e o ordenamento de razões para conceder ou negar a misericórdia não conseguem atender às exigências do modo dominante para precategorizar razões aceitáveis. Para os que promovem este modo, o que importa é preestabelecer conceitos e categorias no sentido de bifurcar a escolha e a categorização de razões. Como dito anteriormente, a individualidade implícita numa consideração caso-a-caso só pode aparecer agora como um parecer categórico predeterminado de material para configurar ligações corretas entre a razão (decoro) e a moralidade (aceitação) na administração da prerrogativa da misericórdia para formas prefixadas de personalidade. O "indivíduo" torna-se uma forma de personalidade que merece a misericórdia por causa de um encaixe com as opções de pareceres categóricos. Mesmo que o encaixe falhe, o fundamento para a misericórdia ainda é supostamente objetivo. Barbados é um país outlier porque seu espaço classificatório e meios para contemplar a misericórdia nãofuncionam como exige este modo de classificação.

Nesta questão, a posição majoritária cita o raciocínio de seus opositores em Reyes v. A Rainha [2002] 2 AC 235, 257, um recurso de Belize.

O Conselho está atento às provisões constitucionais [...] que regem o exercício da misericórdia pelo Governador Geral [...]. Mas não é uma função da sentença e o Conselho Consultivo não é uma corte independente e imparcial [...]. A administração da justiça envolve a determinação de qual punição um transgressor merece, a fixação da sentença apropriada para o crime. A concessão de misericórdia envolve a determinação de que o transgressor não precisa sofrer a punição que ele merece, que a sentença apropriada por alguma razão seja perdoada. A primeira é uma responsabilidade judicial, a segunda, executiva. A oportunidade de pedir misericórdia de um corpo como o Conselho Consultivo não deve assegurar um defeito constitucional no processo de sentenciamento (Hoffmann, Recurso n. 99 de 2002, p. 7).

Contudo, não é apenas uma questão de qual instância analisa a misericórdia. O problema é providenciar uma classificação que estabeleça formas de personalidade dos transgressores antes do julgamento e da sentença. Para essa tarefa, a divergência no Recurso n. 99 mostra que a questão central é o modo de classificação, e não a constitucionalidade da pena de morte em Barbados. A estrutura e o processo classificatórios do país não permitem que o material seja distribuído corretamente para inserir atributos de misericórdia a fim de fazer produtos inter-relacionados de transgressão e transgressores.

Os recorrentes deste recurso não afirmam que seja contrário à Constituição de Barbados que juízes dêem sentenças de morte para aqueles condenados por homicídio doloso, se, tendo considerado todas as circunstâncias relevantes relacionadas com a transgressão e o transgressor, eles considerarem essa sentença justa. A contestação dos recorrentes não é relacionada com a imposição da pena de morte, mas somente com a imposição obrigatória da pena de morte, isto é, a exigência de que os juíres decretem a pena de morte em todos os casos de homicídio doloso, independentemente de quaisquer considerações relacionadas com transgressão e o transgressor que possam atenuar, em algum grau, a seriedade do crime (Julgamento Divergente, Recurso n. 99 de 2002, p. 24, grifos meus).

Portanto, o debate no país sobre a constitucionalidade da pena de morte e a coerência com a Seção 15 (1) e com as convenções sobre direitos humanos não constituem a questão de fundo. Podemos entender melhor as questões trazidas pelos ativistas e pelas cortes quando as percebemos como ferramentas em seus esforços de colocar Barbados, e outras unidades governamentais semelhantes, dentro das práticas de objetividade e racionalidade do modo dominante. A posição divergente esclarece que o objetivo é restringir os meios para estabelecer objetivamente a transgressão, as circunstâncias e os transgressores. Desejado ou não, tornar as pessoas transgredidas em valores calculados de formas de vida é o resultado deste processo. Isso acontece porque os atributos de misericórdia trazidos para a interação entre transgressão e transgressor separam o agravante do atenuante para deduzir a seriedade da transgressão. Circunstâncias relevantes moderam a culpabilidade, porque preconstituem formas utilizáveis de personalidade. Os resultados são coletados em processos que calculam o valor da vida para o transgredido como outro passo em estimar a "seriedade" ou a repreensibilidade moral dos atos cometidos pelos transgressores. Por exemplo, para tornar a idade um agravante do transgredido, o processo emprega a cronologia. No outro extremo da cronologia, por exemplo, matar uma mulher grávida, ou uma que se sabia ou deveria saber estar grávida, torna-se um agravante em alguns casos. Em 
outros, o limite de idade juvenil, e um teto (normalmente 65 anos ou mais) para os idosos, funciona como agravante para determinar a pena capital no assassinato de uma pessoa idosa. Ainda outros elementos estabelecem agravantes para uma diferença de idade entre transgressor e transgredido.

Portanto, aderir ao modo de classificação dominante apenas inicia o processo de bifurcação. Dizer que a vida é sagrada é a parte fácil, como Dworkin (1993) aponta. Dar valor à vida por essa classificação deve pressupor um cálculo, numa estrutura-em-processo "objetiva" de duas ramificações. O conceito humano surge das sobras do cálculo categórico da bondade necessária para que não seja barbaramente desumano. Conseqüentemente, audiências de clemência na ramificação executiva também apenas abrem esse processo para o cálculo categórico das condições para a misericórdia como avaliação de segunda mão da categoria preestabelecida a partir da qual os transgressores são transformados em formas de personalidade. O "imparcial” funciona em relação a transgressores "individuais" já tipificados. Paradoxalmente, o "indivíduo", como conceito e como ser, deve ser abandonado para servir condições pré-formadas de personalidade para categorias previamente merecedoras de misericórdia. Decidir uma sentença de vida ou morte objetivamente requer reformular a individualidade como combinação prefixada de critérios estatutários e não-estatutários para a exclusão inclusiva. A autoridade da razão, quando subordinada ao modo dominante de classificação, torna-se universalismo por outro nome (ver Kenny, 1963; Eron, 1966; Frankfurt, 1971; Hacking, 1986, 1993; Hampton, 1998; Hamacher, 1986; Felice, 1996).

Direcionado por esse modo de classificação, a instância decisória "independente e imparcial" para pedidos de clemência é ilusória. Nos Estados Unidos, testemunhar uma audiência de clemência é assistir a um reprise do processo litigante de duas fases (culpa e sentença). A promotoria cria um minijulgamento (que normalmente ofusca as distinções entre as provas aplicadas no julgamento de duas fases) para lembrar o conselho de clemência dos agravantes e de seus horrores. Nos "pesos e medidas" da promotoria, os atenuantes estatutários e não-estatutários rapidamente convertem-se em agravantes não-estatutários, como freqüentemente reclamam os advogados de defesa.
"Declarações de impacto sobre a vítima" reiteram o cálculo de valor alto que acabam criando categorias diferenciais de vida transgredida. O processo de valorização transforma o luto em capital para avaliar os resultados como justiça recebida ou negada. A defesa e os parentes e amigos do condenado devem "capitalizar" o "trauma" pré-crime e o esperado luto pós-execução para aumentar o valor baixo da forma transgressora de vida. Portanto, a defesa reitera os atenuantes (ou introduz novos) para tentar novamente o processo judicial de segunda fase. Idealmente, a audiência deve considerar se deixar a pessoa viver traz perigos para aqueles que a vigiam e se ela poderia fugir e ser um perigo para o público. Raramente os indícios dessa possibilidade prevalecem sobre o horror dos crimes e a falta de valor da pessoa condenada. Se o encarceramento parece triunfar, o conceito de remorso, considerado falso, desonesto ou muito pouco e muito tarde, pode prevalecer. Alguns estados norte-americanos incluem no seu esquema formal um exame de "periculosidade futura", com "especialistas" estabelecendo indícios, por vários esquemas classificatórios, que o júri deve considerar em sua decisão de sentenciar à vida ou à morte. Claro que isso significa que o processo classificatório precisa de critérios, regras e padrões no sentido de definir e selecionar os especialistas adequadamente. O resultado é uma indústria em crescimento de "especialistas da mitigação", procurando formar conceitos para assistir à fusão vítima e transgressor a fim de produzir "transgressores vitimizados", merecedores de vida.

Apesar do esquema classificatório de "um conceito, uma sentença", a obrigatoriedade proporcionou a criação de um conceito-alvo que trouxesse Barbados para dentro deste processo. Em 1993, num caso jamaicano, o Conselho Privado atacou o conceito de tempo, tornando-o outro conceito-alvo. Uma estipulação de tempo, conhecida como a regra Pratt-Morgan, tornou Barbados e outras unidades governamentais semelhantes sujeitos à comutação das sentenças de morte por violar o limite de tempo. Tendo completado o seu processo interno, mas com recursos ainda pendentes perante o IACHR, Barbados emitiu em 2002 uma sentença de morte. Subseqüentemente, sua corte mais alta, sustentando a regra Pratt-Morgan, reduziu as penas de morte à prisão perpétua, e notou que tanto o tempo passado como a leitura de uma sentença de morte quan- 
do recursos ainda estavam pendentes constituíam castigo cruel e desumano.

Por causa do alto índice de apoio para a pena de morte e para o esquema de sentenciamento obrigatório por uma ofensa em Barbados, as organizações abolicionistas freqüentemente apresentam suas opiniões a respeito do apoio à pena de morte no Caribe, notando que o aumento da criminalidade e da violência tem lamentavelmente convencido seus públicos de que a pena de morte é a melhor maneira de controlar este aumento e proteger a indústria turística. $\mathrm{O}$ poder e as práticas constitucionais dependem menos do nível de apoio para a pena de morte do que dos cidadãos se engajando nessas questões. Tanto emendar a constituição, como tornar as emendas responsivas aos valores locais, dependem do engajamento dos proponentes e dos opositores. O segundo, porém, apoiado pelo Estado, requer menos esforço - votar quando é possível votar, ao passo que grupos locais contrários à pena de morte requerem mais atividade e energia. Assim, para Barbados, o site meetup.com, que lista doze cidades com grupos contrários à pena de morte, não menciona grupo algum que tenha reuniões.

As unidades governamentais que permanecem sob jurisdição do Conselho Privado têm proposto (e, em alguns casos, sancionado) diversas emendas constitucionais no sentido de adequar-se melhor às suas provisões constitucionais. Nos anos de 1970, propostas surgiram para formar uma corte regional de recursos para substituir o Conselho Privado. Embora a pena de morte tenha se tornado um símbolo do legado colonial, apenas recentemente ela se tornou a razão principal explicitada pelos Estados para a utilização da Corte de Justiça Caribenha (CCJ) como corte de ultimo recurso.

\section{Barbados recorre à Corte de Justiça Criminal Caribenha}

Estabelecida em fevereiro de 2001, a CCJ começou a ouvir recursos em Porto Espanha e em Trinidad e Tobago. A página "Perguntas e Respostas" do site da CCJ explica por que a região precisa da corte:

Pergunta: É razoável supor que os Juízes do Conselho Privado, removidos do ambiente social, sejam menos passionais na interpretação e na aplicação da lei? Resposta: Sim! E aqui está o problema! O direito não é um corpo estático de princípios normativos abstratos a ser aplicado mecanicamente para chegar a soluções objetivamente válidas e resolver problemas das relações humanas. O direito é o resultado normativo dos conflitos das interações humanas, baseado em valores sociais determinados coletivamente e geralmente aceitos, e sujeito a um processo de ajuste contínuo a seus ambientes de controle. Conseqüentemente, as pessoas que interpretam e aplicam a lei devem estar antenadas às dinâmicas relevantes da interação social, que determinam a qualidade e a intensidade das relaçoes humanas e os valores que condicionam esta dinâmica. E, com isso, referimo-nos aos valores que nos fazem chorar; os valores que nos fazem felizes ou tristes; os valores que nos tornam pessoas responsáveis, produtivas, criativas, atenciosas, orgulhosas. Em resumo, os valores que condicionam nossa singularidade como povo. Nesta visão, estar removido do ambiente imediato da interação social à qual se aplica a lei facilitaria uma análise menos passional dos eventos humanos e decisões juridicamente objetivas, mas em detrimento do comportamento social desejado e da coesão social (Site www.caribbeancourtofjustice.org/about2.htm).

A missão fundante desafia os pressupostos classificatórios estabelecidos que vinculam objetividade e racionalidade. Porém, para fornecer procedimentos que honrem os valores locais, seja de perto seja mais remotamente, elimina-se a necessidade da classificação. Resta ainda a questão sobre qual modo de classificação a corte poderia elaborar, e se este diferiria do modo dominante. Os resultados desse "vai-vem" dependem muito da administração das restrições já impostas pelas classificações legais que entrelaçam o direito interno e o internacional. $\mathrm{Na}$ medida em que estas classificações dependem do modo dominante de classificação e dos pressupostos pelos quais ele liga objetividade e racionalidade, a corte começa numa grande desvantagem.

Antes de a corte estabelecer uma decisão em seu primeiro caso de pena de morte, que foi um recurso de Barbados, os abolicionistas chamavamna de "corte de carrasco". Eles temiam que o resultado deste caso encorajaria outras unidades governamentais a recorrer à CCJ. Execuções seguiriam, de acordo com os abolicionistas, tornando retrógrada a medida de inação pelo ordenamento categórico, pois os abolicionistas na prática se reassociariam à categoria dos retencionistas plenos. Segundo o criminologista Ramesh Deosaran:

A decisão da Corte de Justiça Caribenha trará repercussões significativas que nos levarão à chamada política 
do Judiciário [...]. Será um julgamento ativista ou o que pode ser chamado de julgamento obstrucionista, seguindo a letra fria da lei, ou uma tentativa de trilhar o caminho do incremento abolicionista da pena de morte por pontos de vista humanitários? (Richards, 2006).

Em 22 de junho de 2006, a CCJ ouviu o recurso de Barbados que pedia o restabelecimento das sentenças de morte no caso do Recurso n. 99. Entre as questões apresentadas no recurso, Barbados notou que a IACHR, as outras convenções de direitos humanos e o tratado que havia assinado em julho de 1978 foram incorporados no direito interno. O Estado argumentou que as provisões nãoincorporadas do tratado não proporcionavam aos cidadãos de Barbados o direito automático de recorrer às instâncias internacionais. Porém, o problema subjacente não era tanto a permissão de acesso às instâncias internacionais, mas sim as restrições de tempo de cinco anos que a regra Pratt-Morgan impunha aos Estados, enquanto não oferecia meios para controlar as conseqüências quando a demora por parte das instâncias internacionais resultava em violação do prazo temporal. Em 8 de novembro de 2006, a CCJ recusou o recurso de Barbados.

O raciocínio que moldou conceitos-chave no Julgamento Conjunto e em julgamentos concomitantes revela os problemas que proporcionam oportunidades para abolicionistas da pena de morte, outros ativistas de direitos humanos e seus aliados na corte internacional de promover a submissão ao modo dominante de classificação. Sob o pretexto do conceito de obrigatoriedade, o conceito de tempo direcionou o engajamento da corte no problema subjacente da "eqüidade" processual, como condição crítica da "justiça natural" (Julgamento Conjunto na 6). Primeiro, com a importância do conceito de tempo sob a influência do conceito de obrigatoriedade por sentenciamento sob o esquema classificatório da pena de morte, a porta classificatória abre com a questão da juridicidade da prerrogativa de misericórdia. O juiz Hayton, restringindo seus comentários sobre o Julgamento Conjunto a esta questão, concorda que avanços na lei moderna têm minado cláusulas de desapropriação que têm a intenção de proteger de revisões judiciais as prerrogativas atribuídas, constitucionalmente ou não, a uma instância na forma de poder discricionário (Hayton na 4).
Responder à questão da revisão judicial com poder discricionário era essencial para responder a questões sobre o papel de tratados não-incorporados no direito interno. $\mathrm{O}$ conceito de tempo sob a influência do conceito de obrigatoriedade serviu para configurar um conceito composto - expectativa legítima - que todos os julgamentos elevavam ao nível de doutrina. Embora concordando que a misericórdia não dá ao indivíduo qualquer direito, o raciocínio que esta doutrina permitiu a tratados não-incorporados e o inevitável fim do prazo PrattMorgan, combinado com a doutrina da expectativa legítima, justificou a decisão do Julgamento Conjunto de recusar o recurso de Barbados. Para Hayton, o raciocínio do Julgamento Conjunto apoiou-se na "necessidade [como] a mãe da invenção, mas a promoção da justiça neste caso particular requer apenas uma invenção incremental da lei" (Hayton na 2). Propondo um raciocínio alternativo para chegar ao mesmo "resultado justo," o juiz Hayton propôs que "a declaração do Julgamento Conjunto deve ter surgido considerando a 'irracionalidade' como barreira para um uso eqüitativo, processualmente falando, da prerrogativa de misericórdia concedida pelo Comitê Jurídico do Conselho Privado, sob as Seções 24 e 78 da Constituição de Barbados" (Hayton na 6). Argumentar a partir do princípio da "irracionalidade", Hayton concluiu, encorajaria a especificação do que deve ser considerado uma quebra da eqüidade processual necessária para caracterizar um resultado como irracional. Se a revisão judicial achar uma quebra irracional, como deve a corte remediar o problema para assegurar a eqüidade processual? A revisão judicial deve conceder poder positivo e negativo à corte? $\mathrm{O}$ poder negativo permitiria que a corte anulasse o resultado, mas requeriria que ela retornasse a questão para uma "nova decisão" elaborada de uma "maneira justa e adequada" (Hayton na 6). Contudo, se a corte concluir que a autoridade não é confiável ("um erro e está fora"), o poder positivo se transferiria ao papel (Hayton na 6).

Em relação a esta sugestão, o problema principal continua a ser: por qual procedimento a revisão pode avaliar a irracionalidade da decisão da autoridade? Assim, os julgamentos de Hayton e outros apontam que a juridicidade não requer que a autoridade dê razões para sua decisão sobre a misericórdia. $\mathrm{Na}$ ausência de a necessidade da autoridade explicar o raciocínio pelo qual chegou à 
irracionalidade discricionária, a corte teria disponível o relatório e outros materiais nos quais a autoridade se baseou. Mesmo assim, a corte não poderia avaliar as possibilidades de injustiça processual pelo "resultado [deste] raciocínio [...] a corte está no escuro" (Hayton na 9). À corte cabe substituir sua análise "objetiva" do material disponível, tanto para avaliar qual deve ter sido o raciocínio irracional da autoridade, como para justificar sua própria racionalidade no que diz respeito a um desfecho alternativo. Para a equiidade processual, isto é apenas a superfície da questão. É improvável que a corte revise um caso em que a autoridade exibiu irracionalidade ao conceder misericórdia. Assim, abrir o raciocínio discricionário à revisão da corte torna-se outra maneira de oferecer oportunidade para o avanço do papel da classificação formal como base para avaliações objetivas adequadas em justificar a racionalidade da eqüidade processual somente pelo viés do desfecho errado.

A juíza Bernard reconhece que a tendência no "direito moderno erodiu o ataque preventivo da cláusula de desapropriação contra a juridicidade" (Bernard na 3). Ela entende as opiniões que o Julgamento Conjunto apresenta sobre as duas justificativas primárias para a erosão - as questões de jurisdição e de justiça natural - como sendo bem aceitas. Uma autoridade que exerce a prerrogativa discricionária ao agir além de sua jurisdição está sujeita a revisões judiciais, e a corte pode anular sua decisão. Contudo, a justiça natural parece ser mais problemática e mais aberta à expansão classificatória. Sob pretexto da sentença de morte obrigatória, a justiça natural indica a natureza lógica da expectativa de que uma pessoa usará todas as opções para permanecer viva, mesmo que as chances sejam pequenas. Lendo as mudanças legais direcionadas ao "conceito de eqüidade", Bernard concorda com o "ponto de vista de que não importa se cláusulas de desapropriação são estatutárias ou constitucionais; os mesmos princípios são aplicáveis com resultados diversos dependendo dos poderes que a cláusula busca proteger". Quando uma cláusula busca proteger a prerrogativa de decidir questões de misericórdia sob a proteção da provisão de sentença de morte obrigatória, Bernard exclama: "quanto mudou em vinte anos! Os tempos e as atitudes mudam!" (Bernard na 14). As mudanças não conferem ao indivíduo o direito à misericórdia, mas estabelecem condições para o exame da eqüidade processual consistente com a doutrina de expectativas legítimas da justiça natural.

Para erradicarem o direito pré-moderno, as tendências permitem um colapso de processo e princípio que equipare o devido processo legal constitucional e a proteção das cláusulas da lei, amplie a justiça natural e permita a revisão judicial, "testando [...] se a matéria da decisão é ajuizável” (Julgamento Conjunto na 69-75, Bernard na 14-17). Com isso, a oposição judicial/não-judicial ganha um elemento moderador, quase-judicial, que classifica funções discricionárias de autoridade. Portanto, embora percebendo que os casos que fogem da abordagem tradicional à prerrogativa da misericórdia não foram diretamente relacionados com a pena de morte, a fuga significa que uma instância interna que tem o poder da discrição deve exercitá-la de forma justa, mesmo que suas funções sejam administrativas e, portanto, quase-judiciais. Assim como uma instância judicial, uma quase-judicial é "obrigada a agir eqüitativamente", o que significa que ela "tem um dever de agir com boa fé e ouvir os dois lados, pois [o dever] está em todos que decidem sobre qualquer coisa" (Bernard na 16 e 18). Por essa classificação, a Corte de Recursos de Barbados, que é o Conselho Privado de Barbados, "foi uma instituição quase-judicial" e "muita discussão centrou-se no que significa "quase-judicial"” (Bernard na 16-17).

Trata-se de uma verdade trivial, mas ela não responde à pergunta sobre o que fazer em situações de poder desigual para "os dois lados". Mesmo com toda a atenção em torno da boa fé e da eqüidade, o teste para a eqüidade processual não estipula como administrar o "dano" com a demora resultante do poder desigual em violar a eqüidade processual. Com a regra Pratt-Morgan de cinco anos, o Estado tem dois anos para concluir seu processo legal. Uma pessoa condenada, recorrendo a uma instância internacional, compatível com a justiça natural e a doutrina da expectativa legítima, tem 18 meses para completar o seu recurso antes do Estado se incumbir da prerrogativa de misericórdia.

A doutrina da expectativa legítima não significa necessariamente que o indivíduo, ele próprio, tenha expectativa do tempo para aguardar o resultado do recurso antes da sentença de morte ou outra punição. Quanto à legitimidade, a expectativa surge quando a ratificação de um tratado cria uma possibilidade substantiva ou processual que antes 
não existia. Atingir uma expectativa legítima derrubando processo e princípio torna o Estado responsável pela capacidade do tempo de converter o processo na formação de conceitos cruéis, degradantes e desumanos. Portanto, exceto quando o Estado revoga a sentença, mesmo que ele não seja responsável pela demora, é o inoportuno que, com sua crueldade, justifica a comutação de sentenças de morte.

Tentando ganhar poder sobre o tempo, antes de a CCJ ouvir o recurso pedido pelo país, fez-se uma emenda na constituição de Barbados. A Seção 15 que se seguiu fixou um prazo, mas anulou a possibilidade de que uma demora, independentemente do tempo, tornasse inconstitucional uma sentença de morte. Embora a mudança não fosse retroativa, e por isso não se aplicasse ao caso perante a CCJ, a questão do tempo era suficientemente crítica para que todos os julgamentos abordassem as implicações pelas quais as instituições responsáveis por demoras cruéis minavam a fé pública no sistema jurídico. Para Bernard, as "diretrizes e os prazos sugeridos em Pratt não são imutáveis ou esculpidos em pedra" (Bernard na 35). O fato de que as diretrizes são suficientemente duras para tornar necessária a comutação da sentença de morte obrigatória no sentido de evitar expectativas legítimas cruelmente frustrantes provocou uma discussão nos julgamentos sobre as desvantagens que o julgamento moral efetivamente unilateral da violação de tempo impunham aos Estados menores e mais pobres.

Sobrecarga de casos e outros fatores não isentam Estados da acusação de crueldade e das conseqüências advindas da violação dos limites de tempo. Assim, essa discussão serviu para enfrentar o desequilíbrio de poder. Por exemplo, o juiz Nelson afirmou que "a sentença de morte obrigatória é prescrita, mas a Constituição previne a sentença de ser executada sem uma audiência de clemência pelo BPC, o qual (ao controlar os precedentes) deve esperar o relatório dos tribunais internacionais que favorecem a abolição antes de decidir sobre a clemência" (Nelson na 15). Em seguida, apontou para a maneira pela qual a regra Pratt-Morgan acrescenta "mais um elemento ao paradoxo [...] [porque] cinco anos depois de uma condenação, uma sentença que é obrigatória deixa de sê-lo" (Nelson na 16). Contra o poder classificatório combinado dos conceitos de obrigatoriedade e tempo, para Estados que reconhecem sua responsabilidade, o juiz Hayton propôs que quando a IAHRC leva "mais de dezoito meses para produzir o relatório para o benefício do homicida, ele e a pessoa condenada devem aceitar a responsabilidade de um prazo maior do que o necessário no corredor da morte, sem que isso signifique uma punição desumana, cruel e proibida, a ser remediada por comutação da sentença de morte: nenhum benefício sem a responsabilidade concomitante" (Hayton na 11). Concluindo que a restrição de tempo como desequilíbrio de poder permite "a todos os homicidas sentenciados à morte, que eles próprios comutem suas sentenças para a prisão perpétua simplesmente fazendo esse pedido à IAHRC - e acabam por minar totalmente a pena de morte constitucional" (Hayton na 11).

Os julgamentos também apontam que o timing, mais até do que o prazo, é um paradoxo no que diz respeito à capacidade do $\mathrm{BPC}$ de comutar crueldade, realizando a audiência de clemência imediatamente depois da condenação. Ao sugerir maneiras de administrar a eqüidade processual, o Julgamento Conjunto primeiro propõe ao BPC que se reúna assim que possível depois do apelo à Corte de Recursos por uma pessoa condenada à morte, com o propósito único de determinar se os membros estão propensos a comutar a sentença. Havendo tal propensão, passaria sua decisão ao Governador Geral; senão, encerraria a reunião sem outras determinações. O BPC teria uma segunda reunião, imediatamente após o fim dos recursos internos ou o fim do prazo para tais recursos. Só faria isso para determinar se os seus membros eram favoráveis à comutação; depois, repassaria sua recomendação favorável ao Governador Geral ou encerraria a reunião, caso não houvesse aceitação da comutação. O BPC não teria mais reuniões até receber recomendação da instância internacional.

Os juízes consideraram vantajosa esta opção de três reuniões. O exercício da função constitucional, se favorecesse a comutação, poderia poupar custos e tempo de litígio para a pessoa condenada e o Estado. Mas o Julgamento Conjunto não a recomendou, pois concluiu que mesmo que a deliberação fosse limitada, uma reunião que não resultasse em comutação poderia endurecer a opinião dos membros, tornando mais difícil para o BPC considerar eqüitativamente a comutação quando ela finalmente recebesse a recomendação da instância internacional (Julgamento Conjunto na 141-143). A recomendação do Julgamento revela um proble- 
ma não-dito, qual seja, o BPC só é livre para exercitar sua autoridade discricionária se a decisão de comutar for um resultado previsto.

Reiterando a necessidade de considerar a misericórdia como parte integral em vez de subsidiária do processo legal - "uma parte essencial de qualquer sistema de justiça civilizado" - o Julgamento Conjunto foi bastante irônico em relação às opiniões do juiz Holmes, dos Estados Unidos, sobre perdões presidenciais (Julgamento Conjunto na 140). Holmes defendeu que a concessão de um perdão "não é um ato privado de benevolência de um indivíduo que tem poder. Ela é parte do esquema constitucional. Quando concedida, é a determinação da autoridade máxima que o bem-estar público será mais bem servido estabelecendo menos do que o fixado pelo julgamento" (Julgamento Conjunto na 141). Naturalmente, isso implica que não conceder um perdão cumpre o mesmo bem outorgado constitucionalmente. Contudo, o problema para audiências de clemência é como inspirar o bem constitucional quando seus adversários insistem que a pessoa precisa primeiro criar a forma certa de personalidade para constituir o transgressor, antes de contemplar a misericórdia para aquele "indivíduo" categórico resultante. Ao recomendar que o BPC deixe de se reunir para exercer, mesmo que de forma fraca, sua função constitucional, o Julgamento Conjunto expôs sua sensibilidade às esperadas respostas internacionais a um resultado "errado", as quais, por sua vez, exporiam o poder constitucional do BPC como uma fraude.

Numa resposta típica dos abolicionistas a um resultado "certo", de acordo com uma declaração dada pela Federação Internacional para os Direitos Humanos (FIDH), eles acolheram "a primeira decisão sobre pena de morte da Corte Caribenha de Justiça no dia 8 de novembro de 2006". Eles também apontam que "o caso foi percebido como um teste para o posicionamento da nova corte sobre a pena de morte". Não mais preocupada com uma corte que permitisse aos "bárbaros" escaparem pela remoção do recurso final do Conselho Privado, a declaração constata que "o CCJ é o órgão jurídico supremo da Comunidade Caribenha". Livre do medo de uma corte que pudesse abrir as porteiras para execuções, as medidas de progresso novamente deixaram Barbados numa categoria favorável. Permanece na categoria "abolição na prática”, pois não houve execuções "desde 1984”, diz Sidiki Kaba, presidente da FIDH, concluindo:

\begin{abstract}
Ao voltar às execuções, Barbados iria contra a tendência geral em direção ao abolicionismo mundial. Barbados será sede amanhã da UE/ACP Assembléia Parlamentar Conjunta. Os holofotes estarão sobre o país, e será uma ocasião excelente, depois dessa decisão importante, de promover um debate público sobre a questão e adotar uma moratória de lege nas execuções, como primeiro passo em direção ao abolicionismo (Site http:/ /www.fidh.org/spip.php?article3812).
\end{abstract}

Com a justiça ao seu lado, nenhuma organização internacional de direitos humanos precisa se perguntar seriamente se os meios pelos quais busca um fim à pena de morte ajudam a dominação imperial. Pelo contrário, os abolicionistas, comprometidos com uma causa moralmente justa, vislumbram a vitória e estão contentes com o desfecho. Se os ativistas sociais locais ou internacionais, preocupados em eliminar a dominação imperialista, devem estar igualmente contentes é outra questão. A forma como eles contestam questões moralmente manchadas pode abrir a porta à prática imperialista, enquanto aqueles que entram pela porta ignoram aquela questão ou pensam que o bem excede qualquer conseqüência adversa.

\section{Conclusão: por qualquer manobra classificatória necessária}

A confiança em formalidade, sobre qualquer outra forma de tomada de decisão "discricionária”, encoraja ataques a conceitos que parecem promover a discrição, como também a falta de objetividade e racionalidade. "Com a sua grande orelha abanando, o jumento não ouve a sua própria história". Modos alternativos de classificação tornam-se irracionais por ordem classificatória, e as decisões conseqüentes tornam-se imorais. Unidades governamentais que estabelecem modos alternativos de produção de esquemas de pena de morte lutam contra os pressupostos do modo dominante, deixando de atingir a abolição total. Independentemente de proporcionarem ou não indícios de que o seu processo classificatório pode produzir resultados similares ou mais "humanitários", elas permanecem como outliers, por mando classificatório além do aceitável para atingir uma ordem moral 
comum (isto é, universalmente homogeneizado). Em termos gerais, um outlier é um desvio extremo de um meio estabelecido. Para a classificação, tratase de uma unidade de homogeneidade heterogênea presumida que não se encaixa nas distinções categóricas permitidas por uma estrutura taxonômica que proporciona a transformação desse amontoado em heterogeneidades homogêneas utilizáveis.

Ocupando uma zona fronteiriça em termos morais, os outliers operam num espaço de práticas bárbaras e desumanas. Mesmo assim, nem todos os desajustados são monstros. Para poder fazer esse tipo de classificação, temos que analisar como cada um usa o modo dominante para vincular a justeza e a moralidade classificatórias. Com isso, os abolicionistas e seus aliados julgam a gama de categorias e subcategorias aceitáveis e necessárias para distinguir os desajustados dos monstros, como objetos e seres que não se encaixam nos cálculos categóricos gerados pelo modo dominante (ver Law, 1991; Haraway, 1992; Williams, 1995; Ritvo, 1997; Golden, 1998).

Onde um esquema formal classifica para matar, a mancha moral de sua tarefa intensifica as indagações sobre as supostas ligações que a classificação pode proporcionar entre objetividade e racionalidade. Contudo, a mancha em si não produz o desafio subjacente. Ao contrário, a investigação da prática de classificação da pena de morte em Barbados sugere que circunstância moral mais importante diz respeito ao fracasso de uma unidade governamental em aderir às diretrizes rigorosas do modo de classificação dominante. Deixar de aderir a práticas formuladoras de objetividade e racionalidade torna qualquer abordagem alternativa vulnerável a acusações de produzir práticas "bárbaras e desumanas". A eqüidade torna-se uma questão de meios em vez de resultados, porque somente um resultado produzido pelas propriedades classificatórias pode passar no exame da eqüidade processual.

Embora, em certo sentido, tudo isso não diga nada mais do que o fato de que unidades governamentais poderosas podem impor suas vontades às menos poderosas, além da força bruta, a exeqüibilidade dessa imposição depende bastante dos meios e dos processos classificatórios empregados por uma superabundância de agentes do poder no sentido de diminuir a variedade de modos aceitáveis de classificação (Lincoln, 1989; Williams, 1995;
Bowker e Star, 1999). As alternativas permanecem porque, para qualquer processo classificatório, por mais que haja esforços formais para aplicar rigidamente os seus requisitos, os classificadores não encontram facilidade em manter distinções conceituais. Bowker e Star afirmam que os classificadores, bem como pessoas que implementam os requisitos do esquema, discordam até mesmo quanto aos requisitos mais simples, já que eles ajustam-nas às tarefas de que são incumbidos. Na prática, ao estabelecer atributos "nucleares" para os conceitos, ou traços definitivos para as categorias, os classificadores continuamente se engajam em batalhas de definição. Transformar um conceito em alvo inicia uma intensa discussão neste sentido, e não o contrário (Trouillot, 2003, pp. 97-116). Isso faz parte de um esforço maior de fixar condições que justifiquem a alternância de momentos de aglutinação e de separação. Nesses momentos, as tarefas e os motivos direcionam os processos de expansão e contração do modo dominante. Os classificadores, como "interessados" ou "brokers do poder", trabalham a aglutinação e a separação para formar conceitos e decidir o que é objetivo enquanto racionalizam as suas decisões.

Como necessidade cognitiva, a classificação sempre será parte da atividade intelectual. Todavia, depender da expansão ou da contração da classificação formal à qual subordinamos os outros enquanto reivindicamos princípios formais superiores contribui ao que Bruce Lincoln chama de "tirania taxonômica” (1989, pp. 131-141). Para os responsáveis por esta tirania, o modo dominante de classificação não recebe sua legitimidade dos indícios de que sua prática proporciona a melhor, ou única, maneira de fugir do "caos" cognitivo de um "mundo real", que é sempre "incompleto" (Brandon, 1982; Brant, 1983; Bruner, 1986). O modo de classificação não se torna dominante por causa de uma preferência estatística dentro e entre as populações (Asenjo, 1988; Cocks, 1989; Lincoln, 1989; Hacking, 1993, 2002; Williams, 1995; Solomon, 1998). Onde o modo predomina, a legitimidade surge de uma gama de classificadores. Como os agentes de poder internacional empregam as opções que o modo oferece para restringir aqueles do poder local ou nacional menos poderosos, os menos poderosos que resistem à submissão se tornam outliers bárbaros. Eles permanecem assim na medida em que lhes falta poder suficiente para resistir às restrições. 
Com a expansão da infra-estrutura da classificação internacional, menos pessoas têm autoridade para participar do estabelecimento de esquemas de classificação formal que moldam as visões de interação humanitária dentro e entre populações. As oportunidades para o debate são nulas, uma vez que os pressupostos sobre abordagens objetivas e racionais às questões moralmente manchadas são predeterminados. O horror da questão torna difícil a contestação das práticas imperiais subjacentes. Todavia, confrontado com o próximo horror moral, o poder local precisará formar seus próprios intelectuais orgânicos. Caso contrário, aqueles que subordinamos em uma determinada questão terão que esperar de braços cruzados, matando-se mutuamente, até que os brokers do poder internacional classifiquem o seu problema como digno de assistência ou intervenção. Os cientistas sociais que se tornam ativistas-eruditos devem, quando investigam a cognição e a classificação em um determinado contexto, ponderar o fato de que a promoção de um modo singular e a diminuição cada vez maior da interação entre modos influenciam adversamente a maneira pela qual a classificação (um aspecto necessário de toda atividade intelectual humana) diminui a capacidade cognitiva criativa num mundo em que os "povos", que diferem sobremaneira em poder econômico e político, tentam sobreviver às percepções inerentemente arbitrárias de cada um.

\section{Nota}

1 Embora uma decisão posterior do Conselho Privado tenha revertido sua decisão sobre a inconstitucionalidade da pena de morte em Trinidad e Tobago, o Estado retirou-se da Convenção Americana sobre Direitos Humanos. Mesmo assim, espera-se que honre as exigências dos casos ouvidos antes de sua retirada, pois sua constituição não permite implicações retroativas desta retirada. A ECCA baseou sua decisão nas interpretações de posições constitucionais da Índia e dos Estados Unidos, além de suas interpretações da IACHR e dos Comitês de Direitos Humanos das Nações Unidas. O importante para a discussão sobre a implicação da classificação é a ênfase da ECCA na necessidade da corte que passa a sentença de ouvir os atenuantes; esta ênfase tem relevância para a questão de se inserir uma qualificação de misericórdia em todo o processo judiciário, e não existe um espaço separado para tal audiência antes da execução.

\section{BIBLIOGRAFIA}

AMNESTY INTERNATIONAL. (2002), "Barbados: proposed executions could constitute murder". Consultado no site http://www. amnestyusa.org/regions / a mericas / documents.do?id=01F04E707B3B49708056, em 28 jun.

(2002), "Barbados: Amnesty International open letter on the death penalty". Consultado no site http://www.amenstyusa.org/ regions/americas/document.do? $\mathrm{id}=80256$ AB9000584FB680256, em 27 ago. (2005), "Urgent action, death penalty/imminent execution". Consultado no site http://www.amnesty.org/ai.nsf/recent/ AMR150052002!Open, em 11 fev.

ASENJO, F. G. (1988), In-between: an essay on categories. Washington, DC, Lanham, MD, Londres, The Center for Advanced Research in Phenomenology/University of Press of America. ATKINS v. Virginia 2002, 536 US 304.

BELLISLE, Martha. (2005), "Court ruling puts many death row cases in question", in Axis of logic: finding clarity in the $21^{\text {st }}$ century mediaplex. Consultado no site http:/ /www.axisoflogic. com/ artman/publish/article_15548.shtml, em 7 fev.

BIRKS, Peter. (1997), The classification of obligations. Oxford/ Nova York, Clarendon Press/ Oxford University Press.

BOLTON, Neil. (1977), Concept formation. Nova York, Pergamon Press.

BOWKER, Geoffrey C. \& Star, Susan Leigh. (1999), Sorting things out: classification and its consequences, Cambridge, MA/Londres, MIT Press.

BRANDON, E. P. (1982), "Rationality and paternalism”. Philosophy, 57: 533-536.

BRANT, Richard B. (1983), "The concept of moral right and its function". Journal of Philosophy, 80 (1): 29-45.

BRUNER, Jerome. (1986), Actual minds, possible worlds. Cambridge, MA., Harvard University Press.

CARIBBEAN COURT OF JUSTICE. (2003), Site www.caribbeancourtofjustice. Porto Espanha, Caribbean Court of Justice. 
. (2006), "Joint judgment, advance copy". CCJ Appeal No CV 2 of 2005, BB Civil Appeal No 29 of 2004, entregue em 8 de novembro de 2006 pelos juízes de la Baptista e Saunder. . (2006), "Judgment, advance copy". CCJ Appeal No CV 2 of 2005, BB Civil Appeal No 29 of 2004, entregue em 8 de novembro de 2006 pelo juiz Bernard.

. (2006), "Judgment, advance copy". CCJ Appeal No CV 2 of 2005, BB Civil Appeal No 29 of 2004, entregue em 8 de novembro de 2006 pelo juiz Hayton.

. (2006), "Judgment, advance copy". CCJ Appeal No CV 2 of 2005, BB Civil Appeal No 29 of 2004, entregue em 8 de novembro de 2006 pelo juiz Nelson.

CHRISTOFIDOU, Andrea. (1995), "First Person: the demand for identification-free self reference". The Journal of Philosophy, 92: 223-234.

COCKS, Joan. (1989), The oppositional imagination: feminism, critique, and political theory. Londres/ Nova York, Routledge.

DEATH PENALTY INFORMATION CENTER. (2005), "Abolitionist and retentionist countries". Consultado no site http://www. deathpenaltyinfo.org/article.php?scid $=$ 30\&did=140, April 29.

DOW, David R. (2005), Executed on a technicality: lethal injustice on America's seath row. Boston, Beacon Press.

DWORKIN, Ronald. (1993), "Life is sacred: that's the easy part". New York Times, May 16: 36.

ERON, Leonard, D. (1966), The classification of behavior disorders, proceedings of the 2nd of a Series of Meetings. Chicago, Aldine Publishing Company.

FELICE, William F. (1996), Taking suffering seriously: the importance of collective human rights. Albany, State University of New York.

FOOT, Phillipa. (1983), "Moral realism and moral dilemma". Journal of Philosophy, 80, 7: 372-98.

FRANKFURT, Harry G. (1971), "Freedom of the Will and the Concept of a Person," Journal of Philosophy, 68 (1): 5-20.

GOLDEN, Stephanie. (1998), Slaying the mermaid: women and the culture of sacrifice. Nova York, Harmony Books.

HACKING, Ian. (2002), Historical ontology. Cambridge, MA/Londres, MIT Press.

. (1993), "Working in a New World: the taxonomic solution", in P. Horwich (ed.),
World Changes: Thomas Kubn and the nature of science, Cambridge, MA, MIT Press. (1986), "Making up people", in M. Heller e D. Welbery, Reconstructing individualism: autonomy, individuality, and the self in Western thou$g h t$, Stanford, Stanford University Press.

HAMACHER, Werner. (1986), "'Disaggregation of the will': Nietzsche on the individual and individuality", in M. Heller e D. Welbery, Reconstructing individualism: autonomy, individuality, and the self in Western thought, Stanford, Stanford University Press.

HAMPTON, Jean. (1998), The authority of reason. Nova York/Cambridge, Cambridge University Press.

HARAWAY, Donna J. (1992), "The promises of monsters: a regenerative politics for inappropriated others", in P. Triechler, C. Nelson e L. Grossberg (eds), Cultural studies now and in the future, Nova York, Routledge.

IDB: COUNTRIES RANKED BY POPULATION. (2005), Site http://www.Census.gov/ cgi-bin/ipc/idbrank.pl, abr.

INTERNATIONAL FEDERATION FOR HUMAN RIGHTS. (2006), "Barbados/death penalty, a landmark death penalty ruling by the Caribbean Court of Justice". Trabalho publicado em 11 de julho (mimeo.).

KENNY, Anthony. (1963), Action, emotion, and will. Nova York, Humanities.

KRONENFELD, David B. (1996), Plastic glasses and church fathers: semantic extension from the ethnoscience traditions. Nova York/Oxford, Oxford Studies in Anthropological Linguistics/ Oxford University Press.

LAW, John. (1991), Sociology of monsters? Power, technology and the modern world. Oxford, Basil Blackwell (Sociological Review Monograph, 38).

LINCOLN, Bruce. (1989), Discourse and the construction of society: comparative studies of myth, ritual, and classification. Nova York, Oxford University Press.

RICHARDS, Peter. (2006), "Caribbean: regional court tested by death penalty case". Inter Press Service News Agency, no site http://www. ipsnews.net $/$ news.asp?idnews $=333732$.

RITVO, Harriet. (1997), The platypus and the mermaid, and other figments of the classifying imagination. Cambridge, MA, MIT Press.

ROBERTS v. Louisiana (1977, 431 US 633) 
SAHLINS, Marshall. (1910), Historical metaphors and mythical realities: structure in the early history of the Sandwich Islands Kingdom. Ann Arbor, University of Michigan Press.

SIMMONS, Shelagh. (2004), "Ramesh, political point-scoring and the death penalty". Trinidad and Tobago News, consultado no site http:/ /www.trinidadandtabagonews.com/selfnews/viewnews, cgi?newsid1026586661, 331,s, publicado em 13 de julho de 2002.

SOLOMON, Julie Robin. (1998), The making of objectivity: Francis Bacon and the politics of inquiry. Baltimore/Londres, Johns Hopkins University.

THE COURT OF APPEAL OF BARBADOS, Judgment of the Lords of the Judicial Committee of the Privy Council, 7 de julho de 2004, no caso Lennox Ricardo Boyce and Jeffery Joseph v. A Rainha, Privy Council Appeal No. 99 of 2002.

THE WORLD FACT BOOK, (2005), Site htttp:// cia.gov/cia/publications/fact book/geos/ ja.html.

THOMAS, R. Murray. (1995), Classifying reactions to wrongdoing: taxonomies of misdeeds, sanctions, and aims of sanctions. Westport, Ct., Greenwood Press.

TROUILLOT, Michel-Rolph. (2003), “Adieu, culture: a new Duty Arises" in _ Global transformations: anthropology and the modern world, Nova York, Palgrave Macmillan.

WALTON, Douglas. (1997), Appeal to Pity: argumentum ad misericordiam. Nova York, State University of New Press.

WILLIAMS, Brackette F. (1995), "Classification systems revisited: kinship, caste, race, and nationality as the flow of blood and the spread of rights", in S. Yanagisako e C. Delaney (eds), Naturalizing power: essays in feminist cultural analysis, Nova York/Londres, Routledge.

WOODSON v. North Carolina (1976) 428 US 280. 
REVISTA BRASILEIRA DE CIÊNCIAS SOCIAIS - VOL. 23 Nº. 68

\section{"DOMINANDO" OS BÁRBAROS \\ BARBADOS, ATIVISMO \\ ABOLICIONISTA E CLASSIFICAÇÃO DA PENA DE MORTE}

\section{Brackette F. Williams}

Palavras-chave: Barbados; Ativismo; Pena de Morte; Classificação; Imperialismo

Contando com a justiça, as organizações internacionais de direitos humanos que trabalham para abolir a pena de morte freqüentemente tratam da questão se suas estratégias fortalecem a dominação imperial. O presente artigo analisa como abolicionistas, comprometidos com uma causa moralmente justa, comemoram vitórias mesmo quando, de outro ponto de vista, suas ações lhes tornam cúmplices em minar o poder constitucional de Estados política e economicamente fracos, os quais, embora inadequadamente, apóiam seus cidadãos em outras lutas pela liberdade e pela justiça. Não tendo poder suficiente para resistir às restrições, na medida em que se expande a infra-estrutura classificatória internacional, cada vez menos pessoas em Estados fracos possuem a autoridade de participar na elaboração das classificações que moldam as visões de interação humanitária no interior de populações e entre elas, e têm que decidir se os direitos conquistados valem o preço da perda da liberdade cognitiva.

\section{"REIGNING" IN BARBARIANS: BARBADOS, ABOLITION ACTIVISM, AND DEATH PENALTY CLASSIFICATION}

\section{Brackette F. Williams}

Keywords: Barbados; Activism; Death penalty; Classification; Imperialism.

With right on their sides, international human rights organizations, working to abolish the death penalty, often do address whether the strategies they devise aid imperial domination. This essay considers how abolitionists, committed to a morally just cause, see victory and are pleased even when, from another view, their actions make them complicit in undermining the constitutional power of politically and economically weak states which, nonetheless inadequately, aid their citizens in other contests for freedom and justice. Lacking sufficient power to resist the bridle, as international classification infrastructure expands fewer persons in weak states have authority to participate in devising the classifications that shape visions of humane interaction within and across population, and must decide whether rights gained are worth the loss of cognitive freedom with which they pay.

\section{"DOMINANT" LES BÁRBARES BARBARES, ACTIVISM ABOLICIONNIST ET CLASSIFICATION DE LA PEINE DE MORT}

\section{Brackette F. Williams}

Mots-clés: Barbares; Activism; Peine de Mort; Classification; Impérialism

Comptant avec la justice, les organisations internationales des Droits de l'Homme, qui travaillent dans le but d'abolir la peine de mort, abordent généralement la question de savoir si leurs stratégies renforcent la domination impériale. Le présent article analyse de quelle façon les abolitionnistes engagés dans une cause moralement juste, commémorent des victoires même quand, selon un autre point de vue, leurs actions les rendent complices dans le minage du pouvoir constitutionnel d'États politiquement et économiquement faibles, qui, quoique de façon inadéquate, soutiennent leurs citoyens dans d'autres luttes pour la liberté et la justice. Ne possédant pas le pouvoir nécessaire pour résister aux restrictions, dans la mesure ou l'infrastructure classificatrice internationale se répand, de plus en plus, moins de personnes dans des États faibles possèdent l'autorité pour participer à l'élaboration des classifications qui moulent les points de vue de l'interaction humanitaire à l'intérieur de populations et entre elles et qui doivent décider si les droits conquis valent le prix de la perte de la liberté cognitive. 